\title{
Nuclear Factor kappa B activation by Ag, Au nanoparticles, CdTe quantum dots or their binary mixtures in HepG2 cells
}

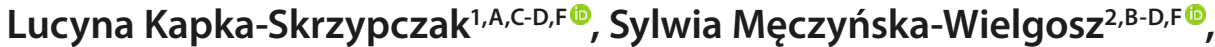 \\ Magdalena Matysiak-Kucharek ${ }^{1, B-C \oplus}$, Magdalena Czajka ${ }^{1, B \oplus}$, Krzysztof Sawicki, ${ }^{1, B \oplus,}$ \\ Marcin Kruszewski ${ }^{1,2, E \oplus}$, Kamil Brzóska ${ }^{2, C-D, F} \oplus$ \\ ${ }^{1}$ Department of Molecular Biology and Translational Research, Institute of Rural Health, Lublin, Poland \\ ${ }^{2}$ Centre for Radiobiology and Biological Dosimetry, Institute of Nuclear Chemistry and Technology, Warsaw, Poland \\ A - Research concept and design, B - Collection and/or assembly of data, C - Data analysis and interpretation, \\ $D$ - Writing the article, E - Critical revision of the article, F - Final approval of article
}

\begin{abstract}
Kapka-Skrzypczak L, Męczyńska-Wielgosz S, Matysiak-Kucharek M, Czajka M, Sawicki K, Kruszewski M, Brzóska K. Nuclear Factor kappa B activation by Ag, Au nanoparticles, CdTe quantum dots or their binary mixtures in HepG2 cells. Ann Agric Environ Med. 2020; 27(2): $231-234$. doi: $10.26444 /$ aaem/120664
\end{abstract}

\begin{abstract}
Introduction and Objective. Nuclear factor kappa B (NF-kB) signalling pathway plays a central role in the regulation of cellular response to stress. The aim of the study was to investigate the ability of silver nanoparticles (AgNPs), gold nanoparticles (AuNPs), CdTe quantum dots (CdTeQDs) or their binary mixtures to stimulate NF-kB binding in HepG2 cells. A dual luciferase reporter system was used to investigate NF-KB binding.

Materials and method. Cells were transiently transfected with a firefly luciferase reporter system and Renilla luciferase expression plasmid as a transfection efficiency control. Twenty- four hours after transfection, the cells were treated with nanoparticles (10 $\mathrm{\mu g} / \mathrm{cm}^{3}$ AgNPs, $10 \mu \mathrm{g} / \mathrm{cm}^{3}$ AuNPs, $3 \mu \mathrm{g} / \mathrm{cm}^{3}$ CdTeQDs) or with $10 \mathrm{ng} / \mathrm{cm}^{3} \mathrm{TNFa}$ as a positive control. Six hours later, the cells were lysed and the activities of the luminescence of firefly and Renilla luciferases were measured using the Dual-Luciferase Reporter Assay System.

Results. AuNPs and CdTeQDs alone significantly inhibited NF-kB binding activity. Co-treatment with AgNPs and CdTeQDs resulted in an additive effect, whereas the presence of AgNPs diminished the inhibitory effect of AuNPs. Interestingly, significant antagonism was observed between AuNPs and CdTeQDs, suggesting a similar mode of action.

Conclusions. Comparison of the NF-KB binding activity induced by the mixtures of NPs suggests that in some cases NF- $\mathrm{kB}$ binding activity might differ from that observed for the NPs alone.
\end{abstract}

\section{Key words}

nanomaterials, NF-KB, dual-luciferase reporter system, nanoparticles binary mixtures

\section{INTRODUCTION}

In recent years, the fast and uncontrolled development of nanotechnology potentiated exposure of humans and the natural environment to nanoparticles (NPs), i.e. nanomaterials with a diameter less than $100 \mathrm{~nm}$. Although the use of nanomaterials could be beneficial to society, their potential unfavourable effects on human health should not be marginalized. Due to their small size and mobility, NPs easily penetrate the human body, crossing natural barriers between organs and entering tissues and single cells.

Recently, numerous scientific studies have described an expressed toxicity of different NPs and have shown the detrimental effects that NPs exert on cells, tissues and the whole organism. Toxicity of silver NPs (AgNPs), cadmiumtellurium quantum dots (CdTeQDs) has been described many times []. On the contrary, gold NPs (AuNPs) are usually reported as having negligible toxicity. Despite an increasing number of studies indicating tremendous possibilities for the use of nanomaterials in daily life, relatively little is known about the risk which they cause for human health.

Address for correspondence: Lucyna Kapka-Skrzypczak, Department of Molecula Biology and Translational Research, Institute of Rural Health, Lublin, Poland

E-mail: lucynakapka@gmail.com

Received: 03.03.2020; accepted: 17.04.2020; first published: 28.04.2020
The nuclear factor kappa B (NF- $\mathrm{KB}$ ) signalling pathway plays a central role in the regulation of cellular response to stress. Although NF- $\mathrm{kB}$ dependent transcription is modulated by different factors, reactive oxygen species (ROS) are among the most potent NF- $\mathrm{KB}$ activators. Since ROS have been proposed as one of the causes of NPs toxicity, it is very likely that NPs also activate the NF- $\mathrm{KB}$ dependent transcription. Indeed, activation of the NF- $\mathrm{KB}$ dependent transcription has been reported by several researchers [1-3]. On the other hand, some NPs have an inhibitory effect on NF- $\kappa B$ activation and dependent gene expression [4].

To-date, the majority of studies conducted on molecular and cellular level have focused on individual types of nanomaterials, treating them as one factor exerting an effect. However, it should be assumed that in the natural environment humans are in contact with a mixture of xenobiotics, including the mixtures of nanomaterials, interactions of which may modulate their effect on the living organisms. Thus, the current study investigates the effects of AgNPs, AuNPs or CdTeQDs, or their binary mixtures, on NF- $\kappa B$ binding activity. 


\section{MATERIALS AND METHOD}

Preparation of nanoparticles and their characterisation. Spherical AgNPs $(20 \pm 5 \mathrm{~nm})$ and CdTe quantum dots (CdTeQDs) $(3.8 \mathrm{~nm}$, emission $650 \mathrm{~nm} \pm 5 \mathrm{~nm})$ were bought from PlasmaChem (Berlin, Germany). AuNPs $(20 \mathrm{~nm} \pm 5 \mathrm{~nm})$ were obtained from NanoComposix (Prague, Czech Republic). Stock solutions of AgNPs and CdTeQDs were prepared as previously described [5]. In brief, nanoparticles $(2 \mathrm{mg})$ were suspended in $800 \mathrm{~mm}^{3}$ of distilled water and sonicated on ice (dose $4.2 \mathrm{~kJ} / \mathrm{cm}^{3}$ ), then $100 \mathrm{~mm}^{3}$ of $15 \% \mathrm{BSA}$ and $100 \mathrm{~mm}^{3}$ of 10x PBS were added immediately. Stock solutions of all tested NPs were prepared and sonicated before each experiment.

Cell Culture. HepG2 cells was purchased from the American Type Culture Collection (ATCC, USA), and kept in EMEM medium (ATCC) with the addition of 10\% FCS (Gibco, USA) in $5 \%$ carbon dioxide atmosphere at the temperature of $37^{\circ} \mathrm{C}$. Asynchronously growing cells in logarithmic growth phase were used in all trials.

Cytotoxicity testing. The impact of NPs on the proliferation of HepG2 cells was measured with Neutral Red (NR) assay. The test was performed as described previously [5]. In brief, HepG2 cells were seeded in 96-well microplates (TPP, Switzerland) at a density of $1 \times 10^{4}$ cells/well in $100 \mathrm{~mm}^{3}$ of culture medium. Twenty-four hours after seeding, cells were treated with increasing concentrations of nanoparticles $\left(1,5,10,25,50,100 \mu \mathrm{g} / \mathrm{cm}^{3}\right)$ for 48 hours. Treated cells were incubated for 3 hours with $100 \mathrm{~mm}^{3}$ of NR mixture $\left(5 \mathrm{mg} / \mathrm{cm}^{3}\right.$ of NR in PBS was thinned 1:100 in the cell culture medium, kept for 12 hours and centrifuged). Next, NR mixture was removed, cells were washed with $150 \mathrm{~mm}^{3}$ of PBS. At the end $150 \mathrm{~mm}^{3}$ of an acid-ethanol mixture $\left(49 \% \mathrm{H}_{2} \mathrm{O}, 50 \% \mathrm{EtOH}\right.$ and $1 \% \mathrm{CH}_{3} \mathrm{COOH}$ ) was pipetted to each well, the microplate was shaken for 15 minutes and optical density was red at $540 \mathrm{~nm}$ in plate reader spectrophotometer Infinite M200 (Tecan, Austria). Not less than 3 independent experiments, each in 6 replicates, were conducted per experimental point.

Transfection and dual luciferase assay. Vector DNA was transiently transfected using Lipofectamine 3000 and P3000 reagent (Invitrogen). $1.1 \times 10^{5}$ cells in $0.5 \mathrm{~cm}^{3}$ culture medium per well were seeded on 24 -well cell culture plates. Next day, $0.75 \mathrm{~mm}^{3}$ of Lipofectamine $3000,1 \mathrm{~mm}^{3}$ of P3000 reagent, $500 \mathrm{ng}$ of Luciferase Reporter Vector (Panomics, USA) containing firefly luciferase gene controlled by a promoter containing $6 \mathrm{NF}-\mathrm{\kappa B}$ binding sites. To standardize transfection efficiency, $25 \mathrm{ng}$ of pGL4.74 Renilla luciferase plasmid (Promega) was added to each well. To the control cells, a control vector lacking NF- $\kappa B$ binding sites was added. Next day, the cells were treated with NPs $\left(10 \mu \mathrm{g} / \mathrm{cm}^{3} \mathrm{AgNPs}\right.$, $10 \mu \mathrm{g} / \mathrm{cm}^{3}$ AuNPs, $3 \mu \mathrm{g} / \mathrm{cm}^{3}$ CdTeQDs) or with $10 \mathrm{ng} / \mathrm{cm}^{3}$ TNF as a positive control. Six hours later, the cells were lysed and the activities of the firefly and Renilla luciferases were measured using the Dual-Luciferase Reporter Assay System (Promega) on a TD-20/20 luminometer (Turner Biosystems), according to the manufacturers' instructions.

Statistical analysis. Statistical significance of differences was evaluated using Student's t-test or ANOVA, followed by a post hoc Tukey's test. The $P$ value less than 0.05 was considered statistically significant.

\section{RESULTS}

NPs cytotoxicity. Cytotoxicity of NPs was investigated by Neutral Red assay (Fig. 1). As expected, AuNPs were barely toxic. It was impossible to calculate a reasonable $\mathrm{IC}_{50}$ value for these NPs, as at concentration $100 \mu \mathrm{g} / \mathrm{cm}^{3}$ the surviving fraction of HepG2 cells was still more than 90\%.


Figure. 1. Toxicity of (A) gold nanoparticles (AuNPs), (B) silver nanoparticles (AgNPs) or (C) CdTe quantum dots (CdTeQDs). Data expressed as a percent of untreated control.

Mean $\pm \mathrm{SD} ; \mathrm{n}=3 ;{ }^{*}$ significant difference from control (Student's $t$-test for dependent values; $P<0.05$. Statistical evaluation performed for raw data) 
AgNPs expressed moderate toxicity with $\mathrm{IC}_{50}$ value of $50 \mu \mathrm{g} / \mathrm{cm}^{3}$. The most toxic of studied NPs were CdTeQDs. Surviving fraction of HepG2 treated with CdTeQDs rapidly decreased, giving an $\mathrm{IC}_{50}$ value of around $3 \mu \mathrm{g} / \mathrm{cm}^{3}$.

NF- $\kappa \mathrm{B}$ binding activity. Activation of the NF- $\kappa \mathrm{B}$ signaling pathway was analysed after treatment with NPs alone or their mixtures. Cells treated with TNF served as a positive control of NF- $\kappa \mathrm{B}$ activation (Fig. 2).

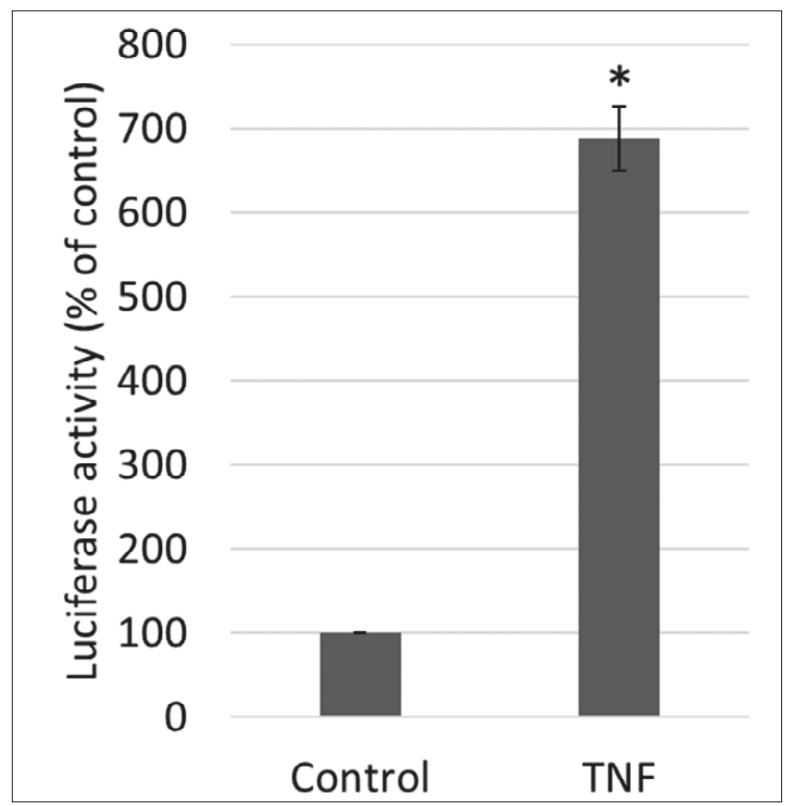

Figure 2. Activity of NF-KB signaling pathway in HepG2 cells treated with $10 \mathrm{ng} / \mathrm{cm}^{3}$ TNF for 6 hours.

Mean $\pm S D ; n=4 ;$ * statistically significant difference between groups (Student's $t$-test for dependent values; $P<0.05$ ).

AgNPs alone had no significant effect on NF- $\kappa$ B activation. On the contrary, treatment with CdTeQDs resulted in significant inhibition of NF- $\kappa \mathrm{B}$ binding activity in HepG2 cells but this effect was not affected by AgNPs presence (Fig. 3). Analysis by two-factor ANOVA revealed no interaction between AgNPs and CdTeQDs, meaning that their effects were additive.

Similarly to CdTeQDs, AuNPs treatment decreased NF- $\kappa \mathrm{B}$ binding activity in HepG2 cells, but this effect was inhibited by the presence of AgNPs (Fig. 4). Interestingly, treatment with the mixture of AuNPs and AgNPs resulted in NF- $\kappa \mathrm{B}$ binding similar to that observed in the control cells, indicating that the presence of AgNPs diminished the inhibitory effect of AuNPs. Indeed, analysis by ANOVA revealed significant interaction between AgNPs and AuNPs. Significant interaction in ANOVA analysis was also observed between AuNPs and CdTeQDs. Both NPs alone significantly diminish NF- $\kappa$ B binding capability, but the effect of AuNPs and CdTeQDs co-treatment did not differ from the effect of each of the NPs alone, suggesting that their interaction was of an antagonistic nature (Fig. 5).

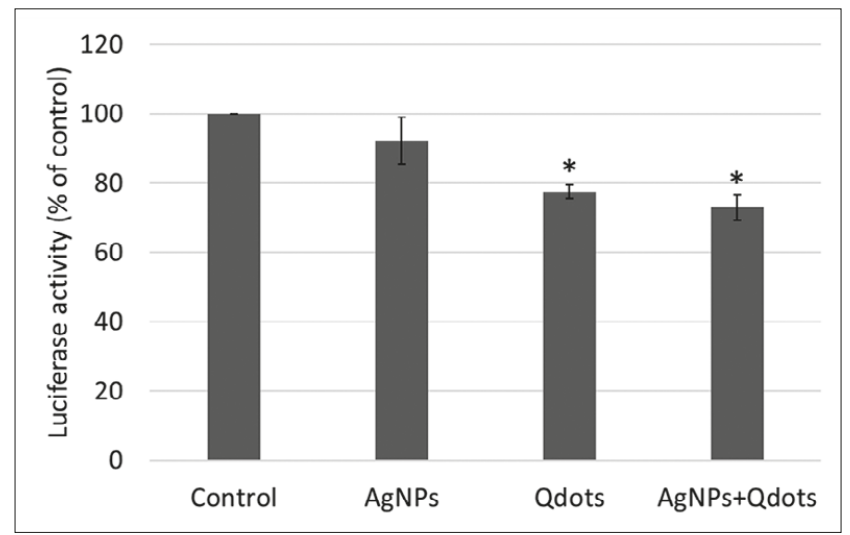

Figure 3. Activity of NF-KB signaling pathway in HepG2 cells treated with $10 \mu \mathrm{g} / \mathrm{cm}^{3}$ AgNPs, $3 \mu \mathrm{g} / \mathrm{cm}^{3}$ CdTeQDs (Qdots) or the mixture of both.

Means $\pm S D ; n=4 ;^{*}$ statistically significant difference versus control or AgNPs groups (ANOVA followed by post hoc Tukey's test; $P<0.05$ ).

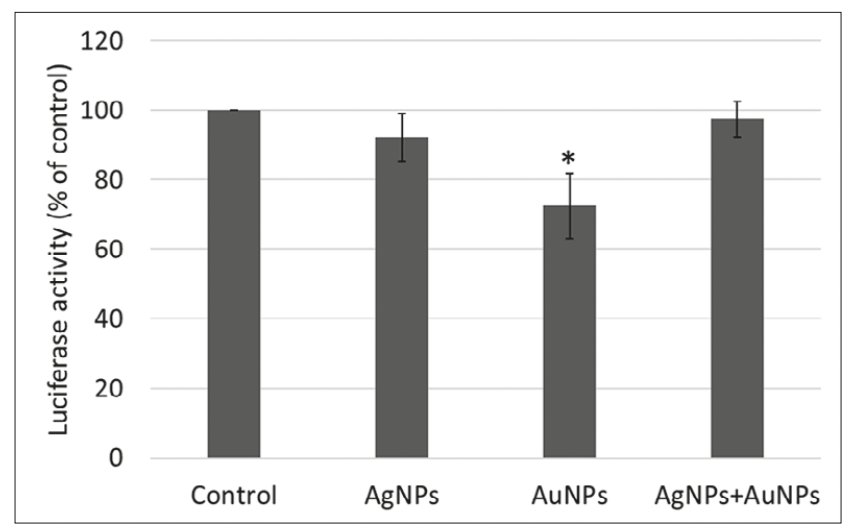

Figure 4. Activity of NF-KB signaling pathway in HepG2 cells treated with $10 \mu \mathrm{g} / \mathrm{cm}^{3}$ AgNPs, $10 \mu \mathrm{g} / \mathrm{cm}^{3}$ AuNPs or the mixture of both.

Means $\pm S D ; n=4 ;{ }^{*}$ statistically significant difference between AuNPs and all other groups (ANOVA followed by post hoc Tukey's test; $P<0.05$ ).

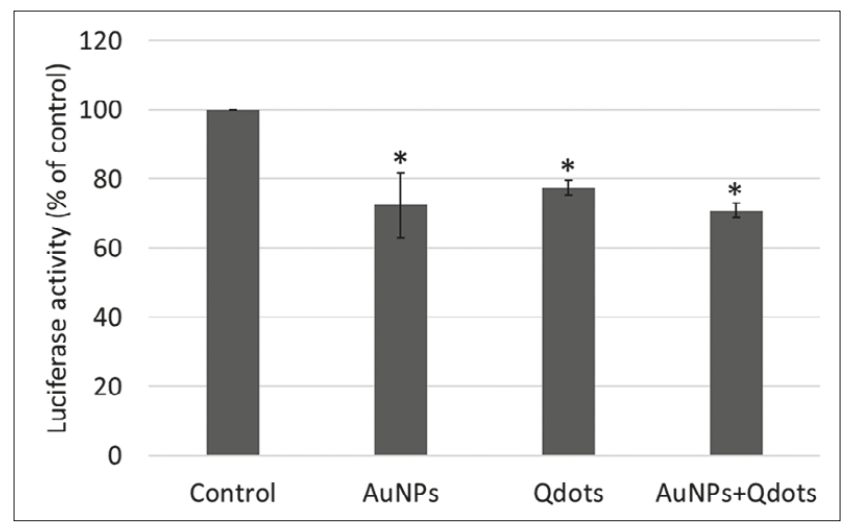

Figure 5. Activity of NF-KB signaling pathway in HepG2 cells treated with $10 \mu \mathrm{g} / \mathrm{cm}^{3}$ AuNPs, $3 \mu \mathrm{g} / \mathrm{cm}^{3}$ CdTeQDs (Qdots) or the mixture of both.

Means $\pm S D, n=4 .{ }^{*}$ statistically significant difference vs. control group (ANOVA followed by post hoc Tukey's test; $P<0.05$ ).

\section{DISCUSSION}

A previous study by the authors of the current study paper showed that silver and gold nanoparticles may interfere with cellular signalling activated by TNF and change the final outcome of TNF action [6]. TNF is a pleiotropic cytokine responsible for different cellular processes, e.g. it 
stimulates survival and proliferation, but it can also trigger an apoptotic or necrotic cellular death. Pro-survival effect of TNF is dependent mainly on activation of the NF- $\kappa \mathrm{B}$ transcription factor, which induces the transcription of a set of pro-survival genes. In the majority of cells, exposure to TNF is lethal only when the NF- $\kappa B$ signaling pathway is inhibited [7]. The current study aimed to discover how NF- $\kappa \mathrm{B}$ is affected not only by individual types of nanoparticles, but also by their mixtures. A real-life scenario involving simultaneous exposure to different types of NPs becomes more and more probable, given the increasing development and use of different types of NPs in industry and medicine.

This study also shows that AgNPs in high concentrations $(100 \mu \mathrm{g} / \mathrm{ml})$ activate the NF- $\mathrm{BB}$ transcription factor and expression of its target genes in HepG2 cells [2]. In the sublethal concentration used in the study, AgNPs did not show any significant effect on NF- $\kappa$ B activity, but neutralized the inhibitory effect of AuNPs. The observed inhibitory effect of AuNPs on NF- $\kappa$ B activity is in line with the well-known anti-inflammatory activity of AuNPs and gold itself [8]. It has been reported that AuNPs inhibits Akt kinase, one of the activators of IKK complex [4]. IKKa and IKK $\beta$ kinases together with the IKK $\gamma$ regulatory subunit form IKK kinase complex, which is the core element and central regulator of the NF- $\kappa$ B cascade [9].

NF- $\kappa \mathrm{B}$ binding activity was also inhibited by CdTe QDs. This observation is in agreement with results of Hu et al. [10], who demonstrated that CdTe QDs selectively inhibit NF- $\kappa B$ activation by blocking the activity of the IKKa and IKK $\beta$ kinases, which results in inhibition of both the canonical and the non-canonical NF- $\kappa \mathrm{B}$ signalling pathways. This explains the antagonistic interaction between AuNPs and QDs observed in the presented study. When the IKK complex is blocked by CdTe QDs, inhibition of its activator Akt by AuNPs cannot result in further decrease in NF- $\kappa$ B activity.

\section{CONCLUSIONS}

The NF- $\kappa \mathrm{B}$ binding activity induced by the mixtures of NPs in some cases differed from that observed for the NPs alone. Although further research is needed to fully understand the molecular mechanisms responsible for the observed effects, careful consideration should be observed during the development of medical and diagnostic applications in which AgNPs and AuNPs are planned to be used simultaneously. This especially applies when AuNPs are planned to be used due to the anti-inflammatory potential.

\section{Acknowledgement}

This work was supported by the National Science Centre from sources for science under commissioned research project No. 2013/09/B/NZ7/03934.

\section{REFERENCES}

1. Shen S, Liu Y, Huang P, Wang J. In vitro cellular uptake and effects of Fe3O4 magnetic nanoparticles on HeLa cells. J Nanosci Nanotechnol. 2009; 9: 2866-2871.

2. Stepkowski TM, Brzoska K, Kruszewski M. Silver nanoparticles induced changes in the expression of NF-kappaB related genes are cell type specific and related to the basal activity of NF-kappaB. Toxicol In Vitro 2014; 28: 473-478.

3. Shi Y, Pilozzi AR, Huang X. Exposure of $\mathrm{CuO}$ Nanoparticles Contributes to Cellular Apoptosis, Redox Stress, and Alzheimer's Abeta Amyloidosis, Int J Environ Res Public Health 2020; 17(3). pii: E1005.

4. Ma JS, Kim WJ, Kim JJ, Kim TJ, Ye SK, Song MD, Kang H, Kim DW, Moon WK, Lee KH. Gold nanoparticles attenuate LPS-induced NO production through the inhibition of NF-kappaB and IFN-beta/STAT1 pathways in RAW264.7 cells. Nitric Oxide 2010; 23: 214-219.

5. Lankoff A, Sandberg WJ, Wegierek-Ciuk A, Lisowska H, Refsnes M, Sartowska B, Schwarze PE, Meczynska-Wielgosz S, Wojewodzka M, Kruszewski M. The effect of agglomeration state of silver and titanium dioxide nanoparticles on cellular response of HepG2, A549 and THP-1 cells. Toxicol Lett 2012; 208: 197-213.

6. Brzoska K, Gradzka I, Kruszewski M. Impact of silver, gold, and iron oxide nanoparticles on cellular response to tumor necrosis factor. Toxicol Appl Pharmacol. 2018; 356: 140-150.

7. Waters JP, Pober JS, Bradley JR. Tumour necrosis factor and cancer. J Pathol. 2013; 230: 241-248.

8. Hornos Carneiro MF, Barbosa F Jr. Gold nanoparticles: A critical review of therapeutic applications and toxicological aspects. J Toxicol Environ Health B Crit Rev. 2016; 19: 129-148.

9. Israel A. The IKK complex, a central regulator of NF-kappaB activation. Cold Spring Harb. Perspect Biol. 2010; 2(3):a000158.

10. Hu Z, Song B, Xu L, Zhong Y, Peng F, Ji X, Zhu F, Yang C, Zhou J, Su $\mathrm{Y}$, Chen S, He Y, He S. Aqueous synthesized quantum dots interfere with the NF-kappaB pathway and confer anti-tumor, anti-viral and anti-inflammatory effects. Biomaterials 2016; 108: 187-196. 